\title{
CONHECIMENTOS PROFISSIONAIS EVIDENCIADOS EM ESTUDOS DE AULA NA PERSPECTIVA DE PROFESSORES PARTICIPANTES
}

\author{
ADRIANA RICHIT \\ ORCID: https://orcid.org/0000-0003-0778-8198 \\ JOÃO PEDRO DA PONTE" \\ ORCID: https://orcid.org/0000-0001-6203-7616
}

I Universidade Federal da Fronteira Sul, Campus Erechim, Rio Grande do Sul, Brasil.

II Universidade de Lisboa, Instituto de Educação, Lisboa, Portugal.

Adriana Richit - Doutora em Educação Matemática pela Universidade Estadual Paulista (UNESP, Rio Claro, SP). Pós-doutora pela Universidade de Lisboa. Professora na Universidade Federal da Fronteira Sul (UFFS), Campus Erechim, Rio Grande do Sul, Brasil. Docente dos Programas de Pós-graduação em Educação e Pós-graduação Interdisciplinar em Ciências Humanas, ambos da UFFS. Coordenadora do Grupo de Estudos e Pesquisa em Educação Matemática e Tecnologias (GEPEM@T). E-mail:<adrianarichit@gmail.com>.

João P. da Ponte - Doutor em Educação pela University of Georgia, Athens, GA, United States. Professor catedrático na Universidade de Lisboa, Instituto de Educação, Lisboa, Portugal.

E-mail:<jpponte@ie.ulisboa.pt >.

RESUMO: O artigo identifica os conhecimentos profissionais evidenciados por professores do ensino básico de escolas públicas de Lisboa participantes em estudos de aula. A investigação, qualitativa e interpretativa, baseou-se em entrevistas semiestruturadas a sete professores, sendo feita uma análise de conteúdo dos seus depoimentos. Os resultados evidenciam que os estudos de aula mobilizaram conhecimentos profissionais de matemática e de didática da matemática. Relativamente à matemática, os professores destacaram que o estudo de aula favoreceu o aprofundamento dos conhecimentos sobre os tópicos abordados a partir da ênfase nas suas propriedades matemáticas. Acerca da didática da matemática, consideraram que os estudos de aula levaram-nos a valorizar o planejamento da aula, a desenvolver a capacidade de analisar e elaborar tarefas matemáticas exploratórias e de promover a comunicação das ideias matemáticas na sala de aula. Consideraram, também, ter desenvolvido a capacidade de identificar os modos de pensar e processos de raciocínio dos alunos e perceber suas dificuldades matemáticas.

Palavras-chave: Conhecimento profissional docente. Estudos de aula. Ensino básico. Desenvolvimento profissional de professor. Didática da Matemática. 


\section{PROFESSIONAL KNOWLEDGE EVIDENCED IN LESSON STUDIES FROM THE PERSPECTIVE OF PARTICIPATING TEACHERS}

ABSTRACT: The article aims to identify the professional knowledge evidenced by basic public school teachers of Lisbon who participated in lesson studies. Underlying these lesson studies was an exploratory approach of mathematical topics. The research methodology is qualitative and interpretive, with data collection by semi-structured interviews to seven teachers and a content analysis of their testimonials. The results show that the lesson studies mobilized teachers' mathematics and didactics of mathematics knowledge. Regarding mathematics, the teachers highlighted that the lesson studies favored the deepening of knowledge about topics covered given the emphasis on the mathematical properties. In regarding to didactics of mathematics, the participants considered that the lesson studies led them to value lesson planning, to develop the ability to analyze and design exploratory mathematical tasks and to promote the communication of mathematical ideas in the classroom. They also felt that they developed their ability to identify students' ways of thinking and reasoning processes, and to perceive their mathematical difficulties.

Keywords: Teachers' professional knowledge. Lesson Study. Basic school. Teacher's professional development. Didactics of mathematics.

\section{INTRODUĈ̣̃O}

A formação profissional docente, inicial e continuada, configura-se como um percurso formativo que visa à constituição estrutural do perfil profissional a formar (neste caso o professor) e a sustentação do processo de desenvolvimento profissional, que é alimentado por um conhecimento profissional específico, o qual interage com uma prática profissional continuada (ROLDÃO, 2007; 2014). No âmbito da educação matemática a formação de professores com responsabilidade no ensino desta disciplina constitui-se em um campo de trabalho muito ativo, em cuja base estão os conceitos de conhecimento e desenvolvimento profissional (PONTE, 2014). O desenvolvimento profissional docente diz respeito ao desenvolvimento da competência profissional do professor em relação às práticas letivas e não letivas, bem como na sua autonomia nas práticas de ensino em sala de aula e como elemento da organização escolar. Nesta perspectiva, o desenvolvimento profissional pode ser promovido por meio de processos formativos que oportunizem ao 
professor a reflexão e a participação em práticas sociais, com forte envolvimento pessoal e suporte dado pelos grupos sociais em que participa (PONTE, 2014). Tais processos são alimentados por determinados conhecimentos profissionais ao mesmo tempo que mobilizam e promovem outros conhecimentos.

O conhecimento profissional docente embasa e orienta diretamente a prática do professor em sala de aula. Trata-se de um conhecimento orientado, principalmente, para "uma atividade prática (...), embora se apoie em conhecimentos de natureza teórica $(. .$.$) e$ também de natureza social e experiencial (...)" (PONTE, 2012, p. 85). Nesta perspectiva, a discussão acerca dos conhecimentos profissionais de professores tem mobilizado diversos estudos, mediante os quais vêm sendo apontadas categorias e dimensões relevantes. Elementos tais como o conhecimento do conteúdo curricular, de didática, de valores e atitudes necessárias à profissão docente e de aspectos da cultura profissional, têm sido frequentemente associados ao processo de desenvolvimento profissional de professores (PONTE e OLIVEIRA, 2002; CANAVARRO, 2003; PONTE, 2012; PONTE et al., 2014). Neste movimento de pesquisas e práticas relativas à formação docente, destaca-se um conjunto de estudos que se dedicam a investigar as possibilidades de aprendizagens e os conhecimentos profissionais evidenciados pelos estudos de aula, abordagem esta que tem priorizado o desenvolvimento profissional do professor em diferentes níveis de ensino e contextos educacionais (STIGLER e HIEBERT, 2016).

Os estudos de aula constituem uma abordagem de desenvolvimento profissional de professores centrada na prática letiva e que assume natureza colaborativa e reflexiva (PONTE et al., 2016; STIGLER e HIEBERT, 2016). Originários do Japão no início do século $\mathrm{XX}$, os estudos de aula popularizaram-se nos Estados Unidos a partir dos anos de 1990 e se disseminaram, desde então, por diversos países. Com isso, os estudos de aula têm interessado pesquisadores em diferentes domínios do conhecimento, os quais têm se dedicado a examinar esta abordagem de desenvolvimento profissional. A partir dos resultados destes estudos, aspectos importantes que se associam às aprendizagens e conhecimentos profissionais de professores têm sido destacados, tais como melhorar (ou aprofundar) o conhecimento do conteúdo e sobre o modo de o ensinar (LEWIS, 2004; FUJII, 2016) e como promover mudanças na prática de sala de aula (OLSON e SPARROW, 2011).

Este artigo tem por objetivo examinar os conhecimentos profissionais de professores evidenciados em estudos de aula, segundo a perspectiva dos participantes. Tendo como base a 
especificidade da dinâmica de desenvolvimento dos estudos de aula, procuramos compreender o modo como os conhecimentos profissionais tomam lugar nas diferentes etapas desta abordagem e como favorecem o desenvolvimento profissional do professor. Os participantes são professores do $1 .^{\circ}$ ao $3 .^{\circ}$ ciclo do ensino básico ${ }^{1}$ de Lisboa, que tomaram parte em estudos de aula em 2013-2014, cujo foco se centrava na abordagem exploratória de temas curriculares da matemática dos respectivos ciclos de ensino.

\section{CONHECIMENTOS PROFISSIONAIS DE PROFESSORES RELATIVOS AO ENSINO DE MATEMÁTICA}

A natureza da ação social de ensinar - concebida como a ação intencional e qualificada do professor na relação entre o conhecimento a adquirir e o sujeito que aprende (ROLDÃO, 2014) - estrutura uma perspectiva de desenvolvimento profissional docente que pressupõe a identificação, a constituição e a mobilização de conhecimentos profissionais necessários à concretização desta prática. De acordo com Ferreira, Vale e Pimentel (2013), Ponte (1995; 2012) e Schoenfeld (2014), a prática profissional, especialmente no ensino da matemática, pressupõe conhecimentos profissionais de distinta natureza, os quais estão no cerne da formação do professor, seja ela inicial ou continuada.

O conhecimento profissional refere-se ao repertório de conhecimentos necessários ao exercício profissional em um determinado campo, considerando-se a especificidade da função neste campo, a identidade profissional da categoria que o constitui, o contexto em que esta função é concretizada e os diversos aspectos que interferem nesta prática e definem esta função. No campo da docência esta perspectiva é consubstanciada em Montero (2005, p.218), para a qual conhecimento profissional diz respeito ao

conjunto de informações, aptidões e valores que os professores possuem, em consequência da sua participação em processos de formação (inicial e em exercício) e da análise da sua experiência prática, uma e outras manifestadas no seu confronto com as exigências da complexidade, incerteza, singularidade e conflito de valores próprios da sua actividade profissional; situações que representam, por sua vez, oportunidades de novos conhecimentos e de crescimento profissional.

As discussões em torno dos conhecimentos profissionais necessários à complexa função de ensinar têm contribuído para a identificação de grupos distintos de conhecimentos, os quais têm orientado a formulação de políticas de formação de professores (ROLDÃO, 2014) e de programas curriculares dos cursos de 
formação inicial (licenciatura) e continuada, assim como têm embasado a constituição de perspectivas distintas de formação e desenvolvimento profissional docente.

Relativamente ao conhecimento profissional docente, Shulman (1986) distingue três categorias principais: conhecimento do conteúdo (content knowledge), conhecimento currícular (curricular knowledge) e conhecimento pedagógico do conteúdo (pedagogical content knowledge). O conbecimento do conteúdo refere-se à base de conhecimentos organizados e consolidados no repertório de conhecimentos profissionais do professor, os quais estão circunscritos em uma determinada área do saber. Para Shulman, o conhecimento do conteúdo vai além do domínio de fatos e conceitos específicos de uma determinada área do conhecimento, pois pressupõe a compreensão das estruturas substantivas, variedade de formas nas quais os conceitos e princípios básicos de uma disciplina são organizados para incorporar seus fatos, e sintáticas, conjunto de formas em que verdades e inverdades são validadas, invalidadas ou estabelecidas. Assim, em sua prática profissional o professor, além de definir as verdades estabelecidas no seu campo de atuação, precisa ser capaz de explicar porque uma proposição em particular é considerada justificada, porque é conhecimento válido e como se relaciona, na teoria e na prática, com outras proposições deste mesmo domínio ou de domínios diferentes (SHULMAN, 1986).

O conhecimento pedagógico do conteúdo vai além do assunto ou tema a ser ensinado. Refere-se a uma forma particular do conhecimento do conteúdo, a qual incorpora aspectos relevantes sobre como ensinar e para ensinar este conteúdo. Esta categoria de conhecimento abrange as formas mais adequadas de representação das ideias inerentes a um assunto, as mais consistentes analogias, ilustrações, exemplos, explicações e demonstrações; isto é, as formas de representar e formular um assunto/ conteúdo que o torna compreensível aos outros. Nesta perspectiva, não há uma melhor forma de representação de um assunto e, portanto, o professor precisa dispor de formas alternativas de representação, algumas das quais derivam de pesquisas enquanto outras originam-se no contexto da prática cotidiana. Esta categoria inclui, ainda, um entendimento sobre o que torna a aprendizagem de um tópico específico fácil ou difícil: as concepções e pré-concepções que os alunos trazem consigo na aprendizagem daquele tópico. Se tais concepções estão errôneas, os professores necessitam conhecer e usar estratégias adequadas para favorecer o entendimento dos alunos (SHULMAN, 1986).

O conbecimento curricular diz respeito a uma ampla variedade 
de programas desenhados para o ensino de assuntos e tópicos particulares em um determinado nível, um aporte de materiais de ensino disponíveis em relação àqueles programas, e um conjunto de características que servem, duplamente, como indicações e contraindicações para o uso de um currículo particular ou materiais do programa em circunstâncias particulares. O currículo e os materiais a ele associados constituem a "matéria médica" da pedagogia, a farmacopeia da qual os professores desenham as ferramentas que apresentam ou exemplificam conteúdos particulares e remediam a avaliação ou a adequação dos resultados dos alunos (SHULMAN, 1986). O autor considera ainda outros conhecimentos profissionais, igualmente importantes: o conhecimento de pedagogia geral, o conhecimento dos alunos e dos seus percursos, o conhecimento dos princípios da organização escolar, finanças e direção e o conhecimento dos fundamentos históricos, sociais e culturais da educação.

No que respeita ao professor de matemática, Ponte (1999) considera que o conhecimento profissional neste campo inclui uma dimensão fundamental, a qual está diretamente relacionada à prática letiva. Trata-se de um conhecimento essencialmente orientado para a ação e que se desdobra em quatro grandes domínios:

\footnotetext{
(1) o conhecimento dos conteúdos de ensino, incluindo as suas interrelações internas e com outras disciplinas e as suas formas de raciocínio, de argumentação e de validação; (2) o conhecimento do currículo, incluindo as grandes finalidades e objectivos e a sua articulação vertical e horizontal; (3) o conhecimento do aluno, dos seus processos de aprendizagem, dos seus interesses, das suas necessidade e dificuldades mais frequentes, bem como dos aspectos culturais e sociais que podem interferir positiva ou negativamente no seu desempenho escolar; e (4) o conhecimento do processo instrucional, no que se refere à preparação, condição e avaliação da sua prática lectiva. Este conhecimento, longe de estar isolado, relaciona-se de um modo muito estreito com diversos aspectos do conhecimento pessoal e informal do professor da vida quotidiana como o conhecimento do contexto (da escola, da comunidade, da sociedade) e o conhecimento que ele tem de si mesmo (PONTE, 1999, p.3).
}

Estes quatro domínios constituem o conhecimento didático, o qual circunscreve os conhecimentos profissionais diretamente relacionados à prática letiva do professor. De acordo com Ponte e Oliveira (2002), há outros domínios que são estreitamente relacionados ao conhecimento didático, tais como o conhecimento sobre o contexto escolar e social e o conhecimento sobre si mesmo enquanto professor.

Relativamente ao conhecimento dos conteúdos de ensino, que diz respeito ao desenvolvimento e aprofundamento de conhecimentos específicos da matemática, sejam eles da matemática curricular ou 
conhecimentos matemáticos mais amplos, Pires (2005, p.33) destaca que este "domínio inclui o conbecimento substantivo (factos, conceitos, princípios, estrutura interna e relações com outras disciplinas) e o conbecimento sintáctico (formas de racioínio, argumentação e validação matemática)". Na mesma direção, Fennema e Franke (1992, p.147) consideram que o professor precisa dispor de conhecimentos amplos e profundos não apenas da matemática que ensina, mas também dos assuntos matemáticos que futuramente irá ensinar aos alunos, pois apenas "este conhecimento completo dos conteúdos matemáticos permite que o professor estruture o seu ensino da Matemática de modo a que os alunos prossigam na aprendizagem". Pelo seu lado, Ball, Thames e Phelps (2008) destacam a necessidade e a relevância do conhecimento matemático para ensinar, por diferenciar-se do conhecimento matemático exigido a outros profissionais. Acrescentam, ainda, que este conhecimento compreende um aporte de conhecimentos necessários à concretização do ensino da matemática em sala de aula.

No Brasil, as discussões sobre os conhecimentos profissionais e o desenvolvimento profissional de professores que ensinam matemática, embora recentes (despontaram no cenário nacional após os anos 2000), têm alargado suas fronteiras no campo da educaçao matemática e também da educação. Apoiando-se em referenciais tais como Shulman (1986), Ponte (1999), Fennema e Franke (1992), Ball, Thames e Phelps (2008), diversas pesquisas têm se debruçado a examinar a especificidade do conhecimento do professor que ensina matemática na educação básica (RICHIT, 2010; FIORENTINI e NACARATO, 2005), assim como apontam para a necessidade de haver uma articulação entre conhecimentos de natureza distinta (RICHIT, 2010; RIBEIRO e OLIVEIRA, 2015), a exemplo dos conhecimentos algébricos e geométricos (RIBEIRO e CURY, 2015), basilares no ensino da matemática. Além desses aspectos, destacam-se trabalhos que focam os conhecimentos que estruturam os currículos dos cursos e programas de formacão docente, e que evidenciam uma fragilidade em relação aos conhecimentos específicos da matemática na formação do professor dos anos iniciais, assim como uma fraca articulação entre conhecimentos pedagógicos e técnico-científicos (GATTTI e NUNES, 2009).

Por fim, em relação às discussões sobre conhecimento e desenvolvimento profissional docente no contexto dos estudos de aula, ressaltamos que esta é uma temática pioneira no Brasil, uma vez que há referência apenas a projetos de pesquisa em andamento da Universidade Estadual de Campinas - Unicamp e Universidade Federal da Fronteira Sul - UFFS. 


\section{ESTUDOS DE AULA E O DESENVOLVIMENTO PROFISSIONAL DE PROFESSORES}

Os estudos de aula constituem uma abordagem de desenvolvimento profissional de professores centrada na colaboração e na reflexão (MURATA, 2011) que têm sido implementados e investigados em países tais como a China (HUANG e LI, 2009; CHEN e YANG, 2013), Estados Unidos (LEWIS, 2002; LEWIS, PERRY e HURD, 2009), Portugal (PONTE et al., 2012; PONTE, 2014; PONTE e QUARESMA, 2016), Inglaterra (DUDLEY, 2012; CAJKLER et al., 2014), Filipinas (EBAEGUIN e STEPHENS, 2014) e Brasil (BALDIN, 2010). Num estudo de aula os professores participantes procuram compreender as dificuldades dos alunos e refletir sobre o modo de promover a sua aprendizagem. Este processo formativo compõe-se de quatro momentos principais, todos eles realizados de modo colaborativo: identificação de um problema de aprendizagem; planejamento de uma aula, designada aula de investigação, visando ultrapassar esse problema; realização dessa aula, acompanhada de observação por toda a equipe participante do estudo de aula; e reflexão sobre a aula, com foco naquilo que foi registrado em face as ações dos alunos (LEWIS, 2002; MURATA, 2011; PONTE et al., 2014). Lewis (2002) explicita do seguinte modo as particularidades de cada uma dessas etapas: formulação de objetivos para a aprendizagem e desenvolvimento dos alunos sobre algum tópico ou tema da matemática; planejamento de uma aula de investigação, criteriosamente pensada para alcançar os objetivos definidos; lecionação dessa aula para uma turma, em que a equipe observa e colhe informações sobre as ações dos alunos; reflexão e discussão sobre os aspectos relativos à aprendizagem e desenvolvimento dos alunos observados e registrados durante a aula, que podem contribuir para a melhorar. No fim destes quatro momentos, se desejável, pode fazer-se novo planejamento, repetindo todo o processo.

Os estudos de aula têm possibilitado resultados muito significativos, pois os professores centram a sua atenção, especialmente, sobre os conhecimentos e capacidades necessárias ao sucesso das atividades de sala de aula, desenvolvendo o seu conhecimento sobre o conteúdo e sobre como ensiná-lo e, também, acerca dos processos de pensamento dos alunos (SIBBALD, 2009). Neste sentido, os estudos de aula propiciam oportunidades formativas, por meio das quais o professor pode refletir sobre a necessidade e pertinência de mudanças na prática profissional (OLSON e SPARROW, 2011; PONTE et al., 2014). Ainda, a 
participação em estudos de aula tem propiciado aos professores aprofundar os conhecimentos matemáticos sobre diversos conceitos e sobre o seu lugar no currículo, debruçar-se sobre diversos modos de organização da aula e diferentes formas de a conduzir, tanto nos momentos de trabalho a pares e pequenos grupos como nos momentos de trabalho coletivo (PONTE et al., 2014), bem como analisar os diferentes tipos de tarefa a propor aos alunos e as suas consequências na aprendizagem (FERNANDEZ e ZILLIOX, 2011; PONTE et al., 2012).

Destacam-se, também, conhecimentos profissionais relacionados à capacidade de observar os alunos, as suas dificuldades e processos de raciocínio (MURATA, 2011; BRUCE et al., 2016), estabelecer e promover relações entre teoria e prática (DUDLEY, 2013), desenvolver a capacidade de avaliar e elaborar tarefas matemáticas exploratórias (PONTE et al., 2014), estabelecer relações entre a prática de sala de aula e os objetivos de aprendizagem e desenvolvimento dos alunos a longo prazo (LEWIS, 2002), promover os processos de comunicação em sala de aula (PONTE e QUARESMA, 2016), desenvolver conhecimentos pessoais do professor e disposição profissional (LEWIS et al., 2009), assim como melhorar a capacidade de avaliar e elaborar planos de aula (LEWIS, 2004; FERNANDEZ e ZILLIOX, 2011).

Na mesma direção, Lewis (2009) estrutura três grupos de conhecimentos a partir de um estudo de aula realizado em uma escola elementar japonesa. O primeiro, Conbecimento do conteúdo da disciplina e seus processos de ensino e aprendizagem - envolve o aprofundamento de aspectos específicos da matemática e também do seu ensino, tais como formas de promover a investigação matemática com os alunos e compreender o seu pensamento matemático, experimentação de novas formas, valorização dos registros (representações) escritos dos alunos na resolução das situações-problema e, ainda, antecipação das estratégias de resolução dos alunos. Desenvolvimento das relações interpessoais entre os professores - a abordagem promoveu o desenvolvimento de um tema de pesquisa compartilhado, os professores negociaram um plano de aula que foi conjuntamente delineado por um grupo, compartilharam suas observações de cada grupo de alunos e conjuntamente atribuíram significado a uma aula que todos observaram, aspectos estes que oportunizaram aos professores modificar as inter-relações entre eles. E desenvolvimento de qualidades e disposições pessoais dos professores - envolve características tais como curiosidade, identidade pessoal como aprendiz e como um pesquisador da prática, motivação para 
modificar a prática e a crença de que as mudanças no ensino podem trazer melhorias para a aprendizagem dos alunos.

Os estudos de aula, pela sua dinâmica muito peculiar em que a colaboração constitui um contexto para favorecer os processos de comunicação entre os participantes e a reflexão sobre a prática profissional de sala de aula, têm sido considerados como importante forma de promover o desenvolvimento profissional de professores em matemática (PONTE et al., 2016; STIGLER e HIEBERT, 2016). $\mathrm{Na}$ mesma direção, Olson e Sparrow (2011) consideram que os estudos de aula fornecem uma estrutura sólida para a aprendizagem profissional do professor, pois podem originar dois tipos de mudança pedagógica: a reflexão crítica sobre suas práticas de sala de aula levaos a desenvolver uma prática investigativa; as práticas de sala de aula são transformadas mediante as discussões promovidas com os pares sobre novas compreensões acerca do ensino. Também Ponte et al. (2012) evidenciam que a participação num estudo de aula possibilita ao professor olhar criticamente para sua prática de sala de aula, considerando os múltiplos processos que a permeiam, e o modo como tal prática pode favorecer a aprendizagem matemática dos alunos. Deste modo, distanciar-se da própria prática e olhá-la de forma crítica é, certamente, uma importante contribuição da experiência vivida no estudo de aula para o desenvolvimento profissional do professor.

Ainda relativamente à valorização e concretização da colaboração e reflexão profissional promovidas em estudos de aula, Quaresma e Ponte (2015) acrescentam que a participação em um estudo de aula desenvolvido com professores do ensino básico, permitiu ao grupo experimentar um processo de formação profissional que se diferenciou por concretizar-se em um contexto de colaboração e centrado na reflexão sobre a prática de sala de aula, focando as dificuldades dos alunos e os seus processos de raciocínio. Nesta abordagem, segundo estes autores, os professores tiveram a oportunidade de conjugar conhecimentos experienciais e conhecimentos provenientes da investigação, o que favoreceu o seu desenvolvimento profissional.

\section{METODOLOGIA DA INVESTIGAC̣ÃO}

Esta investigação segue uma abordagem qualitativa e interpretativa (ERICKSON, 1986), incluindo uma análise de conteúdo (BARDIN, 1977), a partir da qual procuramos discutir aspectos do conhecimento profissional docente evidenciados em estudos de aula, baseando-nos em dados recolhidos por meio de entrevistas realizadas 
com professores participantes. Os entrevistados são sete professores do ensino básico de um agrupamento de escolas públicas de Lisboa que participaram em três estudos de aula ${ }^{2}$ no ano de 2013-2014, cada um dos quais com 12 sessões de cerca de 2 horas, sob a coordenação de uma equipe de professores-pesquisadores do Instituto de Educação da Universidade de Lisboa. Destes professores, que concordaram voluntariamente em colaborar com nosso estudo, três lecionam no $1 .{ }^{\circ}$ ciclo (1C) $-1 .^{\circ}$ ao $4 .^{\circ}$ ano (Idalina, Irene e Marta), ${ }^{3}$ uma é professora do 2. ${ }^{\circ}$ ciclo $(2 \mathrm{C})-5 .^{\circ}$ e $6 .^{\circ}$ ano (Luísa), e três lecionam no $3 .^{\circ}$ ciclo (3C) $-7 .^{\circ}$ ao $9^{\circ}$ ano (Alda, Idália e José). Todos possuem experiência profissional compreendida entre 6 e 15 anos de docência no ensino básico.

A escolha deste grupo justifica-se pelo fato de terem participado de estudos de aula realizados à época em que um novo programa curricular de matemática estava sendo introduzido no ensino básico em Portugal, processo esse que solicitou dos professores a mobilização e o desenvolvimento de conhecimentos profissionais distintos na reorganização dos conteúdos e das práticas de sala de aula. Além disso, evidenciar aspectos do conhecimento profissional docente no contexto dos estudos de aula, decorridos dois anos do processo de formação no qual estiveram envolvidos, constitui-se numa possibilidade de destacar os conhecimentos profissionais mobilizados pelo professor em sua prática profissional e a relevância atribuída a estes conhecimentos. Por fim, é uma forma de valorizar aquilo que os professores percebem sobre seu desenvolvimento profissional em face às experiências formativas por eles vivenciadas, e neste caso, especificamente, nos estudos de aula. Em outras palavras, buscamos dar voz aos professores na discussão sobre os conhecimentos profissionais essenciais ao ensino da matemática e sobre o desenvolvimento profissional do professor no contexto desta abordagem.

Os dados foram recolhidos por meio de entrevistas semiestruturadas, realizadas nos meses de junho e julho de 2016, a partir das quais buscamos evidenciar, segundo a perspectiva dos professores participantes, aspectos relativos aos conhecimentos profissionais em foco nos estudos de aula em que estes professores participaram. As entrevistas foram gravadas em áudio, sendo em seguida objeto de transcrição e textualização, constituindo o material empírico do estudo. Posterior ao processo de textualização, as entrevistas foram enviadas a cada um dos professores para validação do material empírico constituído. A partir da análise que realizamos foram destacados aspectos relativos aos conhecimentos profissionais acerca da matemática e seu ensino, constituindo as duas temáticas discutidas neste texto: matemática e didática da matemática. 


\section{CONHECIMENTOS PROFISSIONAIS EVIDENCIADOS NOS ESTUDOS DE AULA}

\section{Matemática}

Para as professoras dos $1 .^{\circ}$ e $2 .^{\circ}$ ciclos, a dinâmica de desenvolvimento do estudo de aula levou-as a retomar e aprofundar aspectos específicos da matemática. Nos seus depoimentos, as professoras do $1 .^{\circ}$ ciclo assinalam que o estudo de aula lhes trouxe, à altura em que foi promovido, a possibilidade de aprofundarem os conhecimentos sobre os números racionais, que era um tema novo no programa de matemática deste ciclo, introduzido em $2013 \mathrm{em}$ Portugal. Afirmaram, ainda, que este conhecimento lhes daria suporte para desenvolver este tópico da matemática em sala de aula de uma forma consistente e segura, pois era a primeira vez que estavam diante do desafio de o ensinar:

\footnotetext{
Nós de facto tivemos necessidade nós próprios de trabalhar determinadas coisas para depois sabermos como apresentar aos alunos [...], para eles poderem resolver, pois para eles não é fácil. Para o desenvolvimento cognitivo deles nesta altura, portanto, essa temática [números racionais] requer muita abstração e às vezes não é fácil [...]. De facto, todas nós nos preocupávamos muito em saber muito bem aquilo que íamos ensinar, que íamos enfrentar em sala de aula, com aquilo que não sabíamos muito bem [...]. (Idalina, 1C)

Uma coisa que nos preocupávamos muito [era saber muito bem o conteúdo que tínhamos de trabalhar em sala de aula], e muitas vezes nós fomos colocados em situação de sermos nós a resolver determinados exercícios e questões. As formadoras muitas vezes também nos trouxeram exercícios e questões sobre o conteúdo, que nós resolvemos como se fôssemos alunos, com desafios acrescidos. (Irene, 3C)
}

Os depoimentos ressaltam os desafios que o novo programa de matemática trouxe para a aprendizagem dos alunos devido à complexidade dos assuntos a trabalhar neste ciclo, mudança esta que, em contrapartida, impôs às professoras a necessidade de aprofundarem o conhecimento da matemática como forma de se prepararem para os desafios de sala de aula. Acrescentam que este desafio colocou-as diante da necessidade de tornarem-se aprendizes para compreenderem alguns aspectos que, à primeira vista, podem parecer simples. Portanto, experiência no estudo de aula propiciou-lhes conhecer e compreender, com profundidade, o tópico dos números racionais.

Outra professora, por sua vez, destacou que a experiência no estudo de aula oportunizou-lhe perceber que a matemática, por ser considerada um desafio para muitas pessoas, precisa ser retomada e aprofundada pelo professor, para que ele consiga mostrar aos alunos que ela pode ser desafiante e atrativa: 
Acho que consegui cumprir esse objetivo que é perceber o desafio da matemática, porque é uma disciplina que nós temos essa consciência de que temos dificuldade nela [...]. Mas, quando nós temos estado com esse desafio a volta na cabeça, acho que vamos conseguir mostrar essa relação [mostrar que para ser interessante a matemática precisa ser atrativa e desafiante], vamos chegar lá. (Marta, 1C)

Para o grupo do $1 .^{\circ}$ ciclo o aprofundamento do tópico números racionais, propiciado pela dinâmica adotada na etapa de planejamento, permitiu perceber especificidades deste tópico que, na prática cotidiana, acabam por ser deixados de lado ou considerados como de menor importância. Além disso, este aprofundamento propiciou-lhes embasamento para reorganizar a prática profissional, incorporando este novo tópico e novas formas de o abordar.

A professora do $2 .^{\circ}$ ciclo, por seu lado, destacou que o estudo de aula oportunizou-lhe aprofundar o conhecimento matemático relativo ao tópico escolhido, inclusive sobre aspectos que inicialmente ela não havia percebido, e que isto poderia ser explorado em sala de aula com os alunos:

[Inicialmente pensei que não seria interessante, porque julguei dominar o conteúdo dos racionais], depois, quando estávamos a planear a aula, fui-me apercebendo que havia imensas coisas sobre esse conteúdo que podemos explorar com os nossos alunos. E portanto foi mesmo interessante. (Luísa, 2C)

Aspectos relacionados com a matemática especificamente, porém, não foram explicitadas nos depoimentos dos professores do $3 .^{\circ}$ ciclo. Consideramos que isto deve-se ao fato de não terem existido mudanças marcantes no programa de matemática do $3 .^{\circ}$ ciclo, no que respeita ao tópico escolhido para o estudo de aula (equações do 1. ${ }^{\circ}$ grau), ao contrário do que aconteceu no tópico escolhido pelos grupos do $1 .^{\circ}$ e $2 .^{\circ}$ ciclos (números racionais).

Portanto, em relação ao conhecimento da matemática, considerando-se a especificidade do contexto de atuação dos professores participantes, o estudo de aula oportunizou a estes profissionais aprofundar aspectos dos tópicos escolhidos quando, devido a processos de mudança curricular, se verificaram alterações significativas na sua abordagem.

\section{Didática da matemática}

As reflexões dos professores sobre os conhecimentos relativos ao campo da didática da matemática evidenciadas nos estudos de aula apontam aspectos associados a duas dimensões: ao processo de ensino em sala de aula e a aprendizagem matemática dos alunos. 
Relativamente ao processo de ensino em sala de aula, os professores destacaram aspectos do conhecimento profissional que se prendem à valorização do planejamento de aula, às análise e elaboração de tarefas matemáticas de natureza exploratória e, ainda, à promoção da comunicação das ideias matemáticas em sala de aula. No que respeita a aprendizagem matemática dos alunos, os professores evidenciaram aspectos relacionados às dificuldades matemáticas dos alunos, aos modos de pensar e aos processos de raciocínio dos alunos.

Valorização do planejamento de aula. Ao comentarem sobre os aspectos significativos em cada uma das etapas do estudo de aula (planejamento, concretização e reflexão sobre a aula de investigação), as professoras do $1 .^{\circ}$ ciclo evidenciaram que esta abordagem levou-as a experimentar um modo diferente de planejar, em que a colaboração permeou todo o processo, valorizando esta dimensão da prática profissional. Afirmaram que a experiência no estudo de aula levou-as a perceber que o planejamento de uma aula de matemática consiste não apenas em elaborar tarefas para um dado tópico curricular, mas explorar modos diferentes de abordar este tópico:

\footnotetext{
Nós não estávamos ali só para preparar atividades, para trabalhar nas tarefas para os alunos. Mas, estávamos, também, a explorar maneiras de resolver e de abordar esta temática que nós íamos ensinar [...]. Nós nos preocupávamos muito em saber muito bem aquilo que íamos ensinar, que íamos enfrentar em sala de aula, com aquilo que não sabíamos muito bem, para auxiliar um bocadinho sobre essa temática. (Idalina, 1C)
}

O estudo de aula levou-as, também, a valorizar este momento da atividade profissional, pois é uma forma de buscar estruturar, da melhor maneira, o plano de trabalho pedagógico para alcançar o objetivo da aula e adequá-lo às particularidades e necessidades da turma:

Aquilo [...] que me lembro muito bem dessa formação, de facto, é a preparação, porque qualquer tarefa, qualquer atividade era trabalhada até o pormenor. E, portanto, não eram definidos só os objetivos para cada passo, mas tinha que definir muito bem onde se queria chegar. (Irene, 1C)

[A formação ajudou-me a] perceber como se faz um trabalho, uma atividade com compatibilidade com as suas habilidades [dos alunos]. E durante o planeamento, inclusive, foi que estabeleci muito do meu plano de aula e a minha intenção de muitas tarefas e atividades que nos ajudaram a ter ferramentas para construir da melhor forma possível aquele projeto, aquela aula, aquela minha planificação. (Marta, 1C)

Na perspectiva das professoras, planejar consiste em estabelecer um percurso de aprendizagem, tendo por princípio aquilo que se espera em termos de aprendizagem matemática dos alunos e ancorando-se 
em tarefas instigantes e dinâmicas, que conduzam a tais objetivos.

Os professores dos $2 .^{\circ}$ ciclo e $3 .^{\circ}$ ciclos, por seu lado, ressaltaram que o planejamento da aula desafiou-os a repensar alguns aspectos da prática letiva que, muitas vezes, são colocados em segundo plano à medida que o professor adquire experiência profissional e tende a consolidar uma rotina de trabalho que acaba por reproduzir sem muita reflexão ou crítica. Tais aspectos implicam diretamente nos processos de ensino promovidos pelo professor:

O planeamento foi uma parte que achei interessante, [porque] quando estávamos a trabalhar, a pesquisar coisas nos manuais, a pensar naquilo que se pretendia com cada tarefa, percebi que, se calhar, precisamos fazer mais isto. Porque quando temos confiança naquilo que estamos a ensinar, porque julgamos dominar aquele conteúdo, se calhar, deixamos de explorar algumas coisas, de aprofundar. (Luísa, 2C)

[O que mais me marcou] foi o planeamento [...]. É que houve aquele debruçar sobre coisas que ensinamos há uma série de anos. Porque equações é uma coisa que ensinamos quase todos os anos [E o que fez a diferença foi] o parar e olhar: o que está aqui, o que está aqui por detrás? E isto é uma coisa que, se calhar, deixamos de lado com os anos. (Alda, 3C)

Constata-se que, para as professoras do $1 .^{\circ}$ ciclo, a experiência no estudo de aula oportunizou-as perceber a importância e a necessidade do planejamento da aula como forma de se prepararem melhor para o ensino da matemática em sala de aula, considerando as especificidades dos alunos e o objetivo estabelecido para aquela aula. Para os professores do $2 .^{\circ}$ e do $3 .^{\circ}$ ciclo, o planejamento da aula levou-os a refletir sobre a abordagem do tópico a ensinar em sala de aula, o que lhes oportunizou perceber a relevância e as possibilidades deste processo em relação ao ensino que promovem.

Análise e elaboração de tarefas matemáticas exploratórias. Os participantes destacaram que o estudo de aula levou-os a repensar o modo como as tarefas são construídas, precisando estruturar-se sobre objetivos muito claros e definidos. Idalina, do 1. ${ }^{\circ}$ ciclo, destacou que a preocupação do grupo era elaborar uma tarefa (guião), que envolvesse os alunos durante toda a aula e, sobretudo, que esta tarefa os levasse a conversar sobre o que estavam fazendo, que comunicassem suas estratégias e expusessem seu raciocínio:

O planeamento de um guião começou a se fazer quando estávamos lá a fazer nossa aula ao pormenor, quando pensamos em todos os passos, em tudo o que pode bloqueá-los, em tudo que possa se dizer claro que vai bloqueá-los mais e ao mesmo tempo que eles conversem para que as pessoas que lá estão a observar e perceber que eles estão a fazer. Então pensamos em uma história, que tinha começo, meio e fim. E essa história precisava de propor desafios aos miúdos, 
mantê-los envolvidos na atividade e que eles falassem das estratégias, como iriam expor o seu raciocínio (Idalina, 1C)

Os professores dos $2 .^{\circ}$ e $3 .^{\circ}$ ciclos também enfatizaram a preocupação com a elaboração de tarefas interessantes e desafiantes. Acrescentaram que a elaboração das tarefas para a aula de investigação foi uma etapa muito trabalhosa, analisando diferentes tipos de tarefa apresentadas em materiais instrucionais auxiliares e procurando propor tarefas mais adequadas:

[A tarefa exploratória] envolveu um conhecimento mais elaborado [...], porque trouxe algo a mais. [...]. E deu muito trabalho a fazer, porque nós quando fizemos a ficha, nós começamos a fazer pesquisa a vários manuais, ${ }^{4}$ e acabávamos por fazer tarefas muito simples, diretas como aquelas dos manuais. E quanto fizemos a ficha, nós próprios queríamos colocar questões que não estavam bem focadas [...]. E depois em conjunto com a equipa do Instituto de Educação, porque eles também estiveram a dar algum apoio, estiveram também a guiar a nossa reunião, porque fazer aquela tarefa foi um bocado trabalhoso, porque tinha de ser interessante e desafiante. (Luísa, 2C)

E foi um trabalho minucioso preparar aquela tarefa, porque tinha de ser diferente, tinha de envolver os alunos e incentivar a investigação. E fazer este tipo de tarefa é mais trabalhoso, mas depois tem o seu resultado. Foi, como eu disse, foi um bocadinho voltar. Fez-me lá lembrar das cadeiras pedagógicas da faculdade [...]. (Alda, 3C)

Para além destes aspectos, os professores do $3 .^{\circ}$ ciclo destacaram que a elaboração de tarefas de natureza exploratória constituiu-se em um processo evolutivo, de constantes modificações e adaptações, e de negociação entre pares, com vistas de torná-las adequadas ao objetivo proposto inicialmente:

Começamos com uma tarefa e depois fomos falando, fomos discutindo, fomos modificando e fomos mudando. [...] adaptando. Um processo de evolução. Foi havendo uma evolução, fomos discutindo o esboço inicial e fomos melhorando, porque havia uma preocupação que a tarefa fosse interessante e envolvesse os alunos. E no início não foi fácil (Idália, 3C)

De maneira geral, os professores de todos os ciclos pontuaram que a elaboração de tarefas voltadas a abordagem exploratória dos tópicos abordados nos estudos de aula constituiu-se em um desafio, ao mesmo tempo que levou-os a mobilizar conhecimentos relativos aos tópicos matemáticos escolhidos pelos grupos e modos de abordálos, em consonância com os objetivos preestabelecidos. Além disso, puderam desenvolver conhecimentos sobre os diferentes tipos de tarefa apresentados em manuais mediante a análise que realizaram. Para as professoras do $1 .^{\circ}$ ciclo o aspecto preponderante era fazer 
com que os alunos expressassem suas estratégias e processos de resolução, enquanto os demais professores atribuíram centralidade ao processo de investigação viabilizado pelas tarefas e o processo de negociação que permeou a sua elaboração.

Comunicação de ideias matemáticas em sala de aula. Outro aspecto destacado pelos professores, especialmente do $1 .^{\circ}$ ciclo, diz respeito à oportunidade dada aos alunos de comunicar suas ideias, expor suas resoluções e conclusões matemáticas. $\mathrm{Na}$ sua perspectiva, esta dinâmica permitiu-lhes revelar capacidades de alunos considerados com maiores dificuldades:

A partir dessa experiência consegui perceber que é importante incentivar os miúdos a mostrar, a explicar como é que eles resolveram um exercício ou um problema e, se calhar, o professor também vai conseguir perceber se eles sabem aquele assunto e entender os erros deles, e discutir esses erros com os miúdos. E se calhar, eu fiz mais vezes isso, não que eu não fizesse antes, se calhar fiz só com questões pontuais. (Irene, $1 \mathrm{C}$ )

[Uma situação que marcou] foi uma aluna com grandes dificuldades que deu uma resposta completamente surpreendente e ficamos todos ali abismados, com aquela estratégia, senão encantados com essa aluna com mais dificuldade. E na altura fomos ali arrebatados por uma resposta que essa aluna deu, com muitas dificuldades, conseguiu dar ali um click e foi para o quadro e conseguiu atingir o objetivo para aquilo, para aquela pergunta. E isso é uma coisa que eu lembro, na altura chamou muito a nossa atenção. (Marta, 1C)

Conforme afirma Marta, a aula de investigação permitiu que os alunos desenvolvessem as tarefas mediante estratégias particulares de resolução e as expusessem no momento da discussão das resoluções, surpreendendo a professora. Irene, por seu lado, enfatiza a relevância deste aspecto por considerar que é uma forma de evidenciar aquilo que os alunos aprenderam efetivamente, ao mesmo tempo que os erros são assumidos como possibilidade de aprendizagem.

Os professores dos $2 .^{\circ}$ e $3 .^{\circ}$ ciclos ressaltaram aspectos que se prendem à maneira como realizaram o fechamento da aula de investigação, com destaque para a sistematização das conclusões dos alunos, o que remete para a importância de ouvir os alunos e de formalizar, de forma colaborativa, aquilo que é destacado por eles em relação ao que aprenderam:

E depois quando os alunos explicaram o que fizeram e como fizeram, como resolveram aquela tarefa, foi uma parte que gostei imenso, porque meus alunos estavam muito empolgados em mostrar aquilo que tinham conseguido, onde tinham chegado. E nós mesmos conseguimos perceber, saber as estratégias deles. E penso que isto é uma parte importante, fazer o aluno nos dizer, explicar as conclusões dele (Luísa, 2C). 
Eu acho que uma parte importante dessas aulas [aula de investigação] é essa parte final com os alunos, das conclusões, para ver onde chegamos. Feito aquele estudo de aula, depois de ouvir e observar dos alunos, conseguir ver ou perceber o que é que realmente ficou, como eles se sentiram, como eles sintetizaram, [porque o] importante é a organização das conclusões, em que compilamos o que os alunos dos vários grupos disseram, onde é que os vários grupos chegaram e fazer a síntese dessas conclusões. Depois partimos para a análise das conclusões, feita com os alunos, pelos alunos e, talvez, com a intervenção do professor [e isto foi de facto uma das coisas mais interessantes daquela formação] (Idália, 3C).

No grupo de professoras do $1 .^{\circ}$ ciclo, os aspectos indicados emergem da especificidade das tarefas exploratórias, que lhes permitiu envolver os alunos na abordagem do tópico de uma forma diferente e expressarem suas ideias e, sobretudo, na aula de investigação em que os alunos foram solicitados a comunicar suas estratégias, ideias e conclusões matemáticas relativas aos tópicos abordados. Os professores do $2 .^{\circ}$ e do $3 .^{\circ}$ ciclos, por sua vez, indicaram contributos que se prendem à maneira pela qual passaram a valorizar as resoluções das tarefas matemáticas que os alunos propuseram, ao mesmo tempo em que puderam experimentar um modo diferente de evidenciar e sistematizar aquilo que os alunos pensaram e as conclusões que chegaram.

Dificuldades matemáticas dos alunos. Os professores dos três ciclos destacaram que a experiência nos estudos de aula oportunizou-os identificar e compreender as dificuldades dos alunos em matemática na medida que foram desafiados a planejar uma aula a partir destas dificuldades. E este aspecto foi aprofundado ao longo da etapa de planejamento, quando foram colocados a pensar e a prever as dificuldades que os alunos teriam no desenvolvimento das tarefas elaboradas e, também, mediante o desafio de propor estratégias para ajudá-los a superar tais dificuldades.

Para Irene, do 1. ${ }^{\circ}$ ciclo, uma forma de o professor perceber as dificuldades dos alunos é colocar-se como aprendiz, desenvolvendo tarefas e justificando as resoluções como se fosse aluno:

Nós tínhamos que pensar como é que os alunos iriam reagir a essa proposta de trabalho. As dificuldades que eles iriam encontrar [...]. E, portanto, muitas vezes, o facto de nós resolvermos as tarefas, [...] resolvê-las antecipadamente, também nos ajuda a perceber as dificuldades que os alunos vão sentir quando estão perante determinado exercício. (Irene, 1C)

Para Luísa, do 2. ${ }^{\circ}$ ciclo, uma das contribuições do estudo de aula, especificamente da etapa do planejamento da aula, foi perceber que o professor, em sua prática cotidiana, realiza o planejamento de aulas sem conhecer e considerar as dificuldades dos alunos nos tópicos que aborda. 
E quando, na etapa de planear, estávamos ali a falar um bocadinho sobre a aula, fala-se muito sobre os conteúdos, naquilo que os alunos podem responder numa determinada tarefa, mas não sabemos como eles vão fazer. E estamos ali a perceber, sem saber, geralmente, as dificuldades dos alunos. [E o estudo de aula] me ajudou a perceber a maneira como ensino um conteúdo, nas dificuldades dos alunos, as vezes a usar uma nova estratégia. A criar outras tarefas, outras atividades pensando nas dificuldades deles, pronto. (Luísa, 2C)

Os professores do $3 .^{\circ}$ ciclo afirmam que perceber as dificuldades matemáticas dos alunos é um aspecto importante na prática letiva em matemática que pode auxiliar na avaliação, ao mesmo tempo em que requer um trabalho específico por parte do professor:

Acho que é muito importante eu conseguir perceber esse aspeto, aprender sobre as dificuldades deles, sobre o que eles fazem, se conseguiram ou se não conseguiram. E isso nós conseguimos ali na formação. (Alda, 3C)

[Penso que é preciso] dar ênfase àquilo que se passa na sala de aula, para poder avaliar os alunos. [...] Há um esforço [...] de pôr os alunos a pensar, que eles aprendam a pensar [...], a desenvolver o raciocínio. É isso que nós, especialmente ali no estudo de aula, no 3. ${ }^{\circ}$ ciclo, sempre insistimos nisso. (Idália, 3C)

Por fim, sugerem que o professor precisa preocupar-se com aquilo que os alunos sabem e as suas dificuldades, de modo que os processos de formação precisam contemplar estas questões, conforme pontua Idalina: "Nas outras formações nós trabalhamos as coisas da formação, estamos lá a ouvir, estamos a fazer atividades sem perceber, sem ter conhecimento das dificuldades dos nossos alunos e de tudo aquilo que acontece quando estamos a trabalhar com os alunos".

Para as professoras do $1 .^{\circ}$ e do $2 .^{\circ}$ ciclo, o estudo de aula permitiu aprender sobre as dificuldades dos alunos na aprendizagem da matemática, pois exigiu-lhes prever as suas reações mediante as tarefas elaboradas e antecipar as dúvidas, estratégias de resolução, conjecturas e conclusões que viriam a propor, ou seja, levou-os a perspectivar, de forma diferente, o processo de ensinar um tópico da matemática. Os professores do $3 .^{\circ}$ ciclo também consideraram esta questão importante, contudo acrescentaram que além de preocuparse com aquilo que os alunos sabem ou não sabem resolver e antever suas escolhas, é preciso haver um esforço no sentido de colocá-los a pensar, a superar essas dificuldades.

Modos de pensar e processos de raciocínio dos alunos. Os professores evidenciaram conhecimentos sobre estes aspectos na medida em que desenvolveram maneiras de incentivar os alunos a utilizar diferentes estratégias de resolução das tarefas, diferentes formas de representação matemática e diferentes justificações no 
decorrer da aula de investigação. Pontuaram que esta prática lhes permitiu identificar diferentes modos de pensar uma tarefa matemática e distintos caminhos de resolução, e em algumas situações foram surpreendidos pelas estratégias e processos de raciocínio dos alunos:

Eles estavam determinados a falar sobre como é que tinham chegado na resolução [...]. E acho que o que eu introduzi um bocadinho foi, comecei a questioná-los sobre as suas estratégias, a explicar as suas estratégias, sobre como fizeram aquilo. Antes eu acho que eu aplicava sem saber as suas estratégias, eu estava a olhar mais para o cálculo e não para a estratégia [...], e esta formação, portanto, fez-nos perceber os caminhos que eles escolhem para chegar [a resolução da tarefa] (Idalina, 1C)

Eu tinha uma dificuldade em verificar que havia formas diferentes de resolver um mesmo exercício e caminhos diferentes, e tentava levar esses alunos a explicar aos colegas como é que eles tinham achado. Olha, o Pedro já resolveu o exercício e resolveu assim. Oh, Pedro, chega até ao quadro e vem explicar como fizeste. $[\ldots .$.$] . Mas de facto os resultados foram [...] surpreendentes, porque apesar de nós$ trabalharmos até a exaustão [...] como é que [os alunos] iriam resolver àquele exercício, no final, quando [fizemos a reflexão sobre a aula de investigação], os aspectos que nós fomos trazendo sobre o trabalho deles, nos surpreendíamos com processos de resolução que não tínhamos pensado. (Irene, 1C)

A professora Irene, especificamente, comenta que embora no início da formação sentia certa dificuldade em perceber que haviam estratégias e processos de raciocínio distintos para resolver uma tarefa, no decorrer do estudo de aula, sobretudo no momento da discussão coletiva das resoluções das tarefas na aula de investigação na medida em que solicitava aos alunos que explicassem como haviam resolvido as tarefas, conseguiu perceber estes aspectos, os quais foram aprofundados na etapa da reflexão sobre a aula observada.

Os professores do $2 .^{\circ}$ ciclo e do $3 .^{\circ}$ ciclo, por seu lado, acrescentaram que no momento da reflexão sobre a aula de investigação foi possível identificar as escolhas dos alunos e identificar as suas formas de raciocínio:

Ah, eu acho que este aí foi um aspeto muito interessante [...]. No fim, depois de tudo, depois de fazer uma reflexão sobre tudo, [...] conseguimos identificar todas as escolhas dos alunos. (Luísa, 2C)

E depois lembro-me que também que fizemos, que acabamos por analisar também resoluções dos alunos de outras tarefas, pronto, que na altura as formadoras levaram e o olhar, a perspetiva de raciocínio que os alunos fizeram, lá está. [...]. E na formação focávamos naquilo e, portanto, havia uma oportunidade que não há no dia a dia de aprofundar tantas coisas e ver outras perspetivas. [...] Foi-se muito à raiz das coisas. (Alda, 3C)

Segundo os depoimentos, a abordagem exploratória de 
tópicos da matemática promovida no estudo de aula propicia ao professor identificar diferentes modos de pensar dos alunos, assim como perceber que o ensino da matemática precisa promover a participação ativa dos alunos neste processo, oportunizando-os expressar e discutir suas estratégias e modos de pensar e, também, refletir sobre as ideias e estratégias dos outros. Assim, a dinâmica do estudo de aula favoreceu aos participantes estudar sobre processos de raciocínio e, principalmente, perceber que os alunos podem seguir processos de raciocínios distintos e, às vezes, surpreendentes para resolução de uma mesma tarefa.

Sumarizando, no contexto do estudo de aula os professores evidenciaram conhecimentos profissionais relativos à matemática e a didática da matemática, conhecimentos estes que assumiram centralidade nas diferentes etapas do estudo de aula e, sobretudo, na reorganização da prática letiva mediante a implementação do novo programa curricular de matemática, favorecendo, portanto, o seu desenvolvimento profissional. Além disso, este desenvolvimento sustenta-se em um trabalho colaborativo e reflexivo, em que os professores partilharam a preocupação com as dificuldades dos alunos e com os desafios advindos com o novo programa de matemática, centrado na elaboração e concretização de uma aula voltada à abordagem de tópicos matemáticos.

\section{DISCUSSÃO E CONCLUSÃO}

Os resultados mostram que os professores participantes nos estudos de aula salientam conhecimentos profissionais relativos a dois domínios principais: matemática e didática da matemática. Relativamente ao conhecimento da matemática, entendendo-o numa perspectiva que vai além da matemática a ser ensinada em sala de aula (BALL et al., 2008; FENNEMA e FRANKE, 1992) e que foca o lugar deste conhecimento no currículo (PONTE et al., 2014), os professores dos $1 .^{\circ}$ e $2 .^{\circ}$ ciclos destacam que o estudo de aula favoreceu o aprofundamento dos seus conhecimentos sobre números racionais, tema que estava a ser objeto de uma nova abordagem curricular. $\mathrm{Na}$ verdade, no que diz respeito à matemática, os professores destes ciclos destacaram aspectos que evidenciam aprendizagens sobre o tópico abordado nos estudos de aula, que se concretizou mediante o aprofundamento das suas propriedades, considerando-se aspectos e relações matemáticas que muitas vezes negligenciavam. Os professores do $3 .^{\circ}$ ciclo, não destacaram aprendizagens significativas 
neste campo, mas valorizaram a reflexão sobre as propriedades matemáticas específicas dos conceitos matemáticos em jogo.

Deste modo, os professores indicam que a dinâmica do estudo de aula, sobretudo a etapa de planejamento da aula de investigação, propiciou-lhes retomar os seus conhecimentos de matemática, explorando as suas especificidades e aprofundando alguns aspectos. Para os professores, a dinâmica do estudo de aula levou-os a mobilizar e aprofundar conhecimentos profissionais de matemática necessários à prática letiva (PONTE e OLIVEIRA, 2002; PONTE et al., 2014). Este aprofundamento permitiu-lhes reestruturar a prática profissional mediante a pressão externa exercida pela implementação do novo programa curricular de matemática. Em outras palavras, este conhecimento profissional específico, mobilizado no âmbito dos estudos de aula, promoveu o desenvolvimento profissional destes professores na medida em que interagiu com os conhecimentos da prática cotidiana (ROLDÃO, 2007, 2014). Este desenvolvimento concretizou-se devido à dinâmica do estudo de aula, que oportunizou aos participantes a reflexão e a participação em uma experiência formativa com forte envolvimento pessoal e suporte dado pelo grupo (PONTE, 2014).

No que se refere à didática da matemática, concebida como dimensão central da formação e prática docente em matemática (PONTE, 1999; PONTE e OLIVEIRA, 2002; PIRES, 2005), os participantes indicaram que os estudos de aula favoreceram o desenvolvimento de conhecimento sobre aspectos associados ao 'ensino da matemática em sala de aula', valorizando o planejamento da aula, desenvolvendo a capacidade de analisar e elaborar tarefas matemáticas exploratórias e de promover a comunicação das ideias matemáticas dos alunos. $\mathrm{Na}$ sua perspectiva, os estudos de aula promoveram também o seu conhecimento relativo à 'aprendizagem matemática dos alunos', levando-os a desenvolver a capacidade de identificar os modos de pensar e os processos de raciocínio dos alunos e de perceber e considerar as suas dificuldades matemáticas.

Em relação ao 'processo de ensino em sala de aula', os participantes dos estudos de aula destacaram aspectos que os levaram a valorizar o planejamento de aulas, conhecimento este de natureza instrucional e considerado essencial à prática letiva (PONTE, 1999; FERNANDEZ e ZILLIOX, 2011; PONTE et al., 2012; PONTE et al., 2014), indicando que o planejamento consiste em estabelecer um percurso de aprendizagem da matemática para os alunos, tomando por princípio as suas dificuldades e aquilo que se espera com a aula. Acrescentaram, também, a importância e a necessidade do planejamento 
como forma de se prepararem melhor para o ensino em sala de aula e a possibilidade de aprofundamento de tópicos da matemática a ensinar.

Os resultados apontam, também, aspectos do conhecimento profissional relacionados com a análise e elaboração de tarefas exploratórias, os quais foram evidenciados nos estudos de aula. Os participantes assinalam que o estudo de aula, particularmente a etapa do planejamento, levou-os a mobilizar e aprofundar conhecimentos sobre os diferentes tipos de tarefa apresentados em manuais (PONTE et al., 2014) e sobre a elaboração de tarefas exploratórias (FERNANDEZ e ZILLIOX, 2011; PONTE et al., 2012; PONTE et al., 2014), destacando seus limites e possibilidades em relação à promoção de investigações matemáticas pelos alunos. Este aspecto permitiu-lhes elaborar tarefas que consideram mais adequadas, com focos mais definidos. Acrescentam, porém, que as tarefas exploratórias precisam, além de contemplar os objetivos estabelecidos para a aula de matemática, levar os alunos a conversar sobre aquilo que fazem quando resolvem uma tarefa, a comunicar suas estratégias, expor suas conjecturas e raciocínios e realizar investigações matemáticas.

Outro aspecto evidenciado pelos professores participantes nos estudos de aula diz respeito aos modos de promover a comunicação das ideias matemáticas em sala de aula, conhecimento este de natureza instrucional e basilar à prática profissional (PONTE, 1999; QUARESMA e PONTE, 2015). No contexto da participação nos estudos de aula, este conhecimento foi evidenciado mediante a necessidade de levar os alunos a comunicar suas ideias, expor suas resoluções e conclusões matemáticas mediante a resolução de tarefas específicas (PONTE et al., 2012; QUARESMA e PONTE, 2015; PONTE e QUARESMA, 2016), dinâmica esta que permitiu aos professores participantes revelar capacidades de alunos considerados com maiores dificuldades. Além disso, a dinâmica da etapa de discussão coletiva das resoluções das tarefas matemáticas, no âmbito da aula de investigação, constituiu-se em uma possibilidade de valorizar as resoluções propostas pelos alunos e de promover uma sistematização dos tópicos abordados, partindo das suas conclusões.

Os resultados evidenciam, ainda, conhecimentos profissionais associados à 'aprendizagem dos alunos em sala de aula', com destaque para aspectos relativos à capacidade de identificar as dificuldades matemáticas e as estratégias de resolução dos alunos (LEWIS, 2009; BRUCE et al., 2016; MURATA, 2011; PONTE et al., 2012) e observar os modos de pensar e os processos de raciocínio dos alunos (LEWIS, 2009; SIBBALD, 2009). Este conhecimento sobre 
o aluno, seus processos de aprendizagem, interesses, necessidades e dificuldades (SHULMAN, 1987; PONTE, 1999), assumiu centralidade nas diferentes etapas dos estudos de aula na medida em que os participantes precisaram de mobilizá-los e aprofundá-los, em um processo prolongado, colaborativo e reflexivo em torno da abordagem dos tópicos considerados.

$\mathrm{Na}$ perspectiva dos participantes, os estudos de aula permitiram-lhes aprender sobre as dificuldades dos alunos na aprendizagem da matemática, pois exigiu-lhes prever as suas reações mediante as tarefas elaboradas e antecipar as dúvidas, estratégias de resolução, conjecturas e conclusões que viriam a propor, ou seja, levou-os a perspectivar de forma diferente o processo de ensinar um tópico da matemática. Indicaram que este aspecto foi retomado na discussão coletiva que encerra a aula de investigação, em face a qual puderam identificar e compreender as dificuldades dos alunos. Por último, destacaram que esta atividade levou-os a preocupar-se com aquilo que os alunos sabem ou não sabem resolver e antever suas escolhas, concluindo que o professor precisa procurar colocá-los a pensar, de modo a superar essas dificuldades.

Foram ainda evidenciados aspectos do conhecimento profissional ligados à capacidade de identificar e compreender diferentes modos de pensar e processos de raciocínio dos alunos. Os professores revelaram que a etapa de planejamento da aula de investigação, especialmente a elaboração de tarefas exploratórias, evidenciou conhecimentos relacionados aos modos de pensar e processos de raciocínio dos alunos (LEWIS, 2009; MURATA, 2011; BRUCE et al., 2016), na medida em que foram solicitados a antecipar as estratégias de resolução dos alunos, seus raciocínios e possíveis erros e a pensar em estratégias de atuação a considerar. Este conhecimento foi aprofundado na aula de investigação, na medida que os alunos foram incentivados a utilizar diferentes estratégias de resolução nas tarefas, a recorrer a diferentes formas de representação matemática e propor diferentes justificações para suas resoluções. Os professores indicaram, ainda, que a discussão das resoluções, no momento final da aula de investigação, consolidou este aspecto, uma vez que ao solicitar que os alunos explicassem os caminhos percorridos até a formulação das suas conclusões, conseguiram perceber os conceitos e representações matemáticas tomados como ponto de partida e, também, os distintos caminhos de resolução que os levaram às conclusões socializadas.

Em conclusão, os estudos de aula levaram os professores a desenvolver maneiras de incentivar os alunos a expressarem suas 
ideias e conjecturas matemáticas, favorecendo a sua participação ativa na aula. Tais aspectos, que exigem do professor a capacidade de estabelecer relações entre a prática de sala de aula e os objetivos de aprendizagem e desenvolvimento dos alunos a longo prazo (LEWIS, 2004), indicam mudanças na prática profissional do professor em relação ao ensino que realizam e ao modo pelo qual promovem a participação dos alunos na aprendizagem da matemática.

Consideramos, ainda, que o tempo decorrido desde a finalização do estudo de aula permitiu aos professores participantes distanciar-se da experiência proporcionada por este processo formativo, olhando de forma crítica e reflexiva para o processo que os envolveu e sobre o próprio estudo de aula. A reflexão dos professores sobre os conhecimentos profissionais evidenciados nesta abordagem, olhando-os decorridos dois anos da sua realização, possibilitou-nos identificar aspectos originados no contexto da prática cotidiana, bem como identificar aspectos que têm a ver com pressões externas e, ainda, aspectos relativos à dinâmica de desenvolvimento do estudo de aula. Em seu conjunto, estes conhecimentos interagiram nas diferentes etapas dos estudos de aula, bem como na prática cotidiana do professor, favorecendo o seu desenvolvimento profissional.

Consideramos, portanto, que os resultados do nosso estudo podem sinalizar perspectivas para a formação de professores de matemática no cenário nacional, pois a dinâmica do estudo de aula pode oportunizar aos participantes vivenciar situações de trabalho colaborativo, que possibilita o crescimento profissional a partir do diálogo, do apoio mútuo, incentivo pessoal e da troca de experiências entre pares. Pode ainda favorecer mudanças na prática profissional em matemática na medida em que os professores são encorajados a experimentar uma nova prática, nomeadamente, a aula de investigação, em que experimentam novas abordagens, novos recursos e novas estratégias de sala de aula, atribuindo aos alunos um papel diferente no processo educativo. Da mesma forma, o estudo de aula, mediante o planejamento colaborativo e reflexivo da aula de investigação e depois a reflexão sobre esta aula, pode levá-los a refletir sobre a própria prática, questionando aspectos culturalmente instituídos nos contextos escolares e em suas crenças e predisposições sobre o ensino da matemática.

Por fim, o estudo de aula revela-se uma abordagem de formação docente em matemática substancialmente diferente das abordagens predominantes nas escolas e redes de ensino brasileiras, por favorecer o trabalho coletivo e ativo dos professores e, sobretudo, por contemplar profissionais da mesma área e nível de ensino, 
atendendo suas necessidades profissionais mais específicas em relação aos conteúdos de ensino e modos de os ensinar. Da mesma forma, pode oportunizar aos professores trabalharem coletivamente no planejamento de uma aula (a aula de investigação), que busca situar problemas particulares de aprendizagem matemática dos alunos. Além disso, pela sua estrutura e dinâmica de desenvolvimento, o estudo de aula pode ser implementado em contextos educacionais variados por mostrar-se passível de adaptação a realidades culturais distintas.

\section{REFERÊNCIAS}

BALL, D.L.; THAMES, M.H.; PHELPS, G. Content knowledge for teaching: What makes it special? Journal of Teacher Education, n. 59, v.5, p. 389-407, 2008.

BARDIN, L. Análise de conteúdo. Lisboa: Edições 70, 1977.

BRUCE, C.D.; FLYNN, T.C.; BENNET'T, S. A focus on exploratory tasks in lesson study" The Canadian "Math for Young Children' project. ZDM-The International Journal on Mathematics Education, n. 48, v.4, 2016.

CANAVARRO, A.P. Práticas de ensino da Matemática: Duas professoras, dois currículos. (Tese de Doutoramento, Instituto de Educação, Universidade de Lisboa, Portugal), 2003.

CAJKLER, W.; WOOD, P.; NORTON, J.; PEDDER, D. Lesson study as a vehicle for collaborative teacher learning in a secondary school. Professional Development in Education, n.40, p. 511-529, 2014.

CHEN, X.; YANG, F. Chinese teachers' reconstruction of the curriculum reform through lesson study. International Journal for Lesson and Learning Studies, n. 2, v.3, p. 218236, 2013.

DUDLEY, P. Teacher learning in lesson study: What interaction-level discourse analysis revealed. Teaching and Teacher Education, n.34, p. 107-21, 2013.

DUDLEY, P. Lesson study development in England: From school networks to national policy. International Journal for Lesson and learning Studies, n.1, v.1, p. 85-100, 2012.

EBAEGUIN, M; STEPHENS, M. Cultural challenges in adapting lesson study to a Philippinese setting. Mathematics Teacher Education and Development, n.16, v.1, p. 43-64, 2014.

ERICKSON, F. Qualitative methods in research on teaching. In: WITTROCK, M. C. (ed.) Handbook of Research on teaching. $3^{\text {rd }}$ ed. New York, NY: Macmillan, 1896. p.119-161

FENEMMA, E.; FRANKE, M. L. Teachers' knowledge and its impact. In: GROWS, D.A. (ed.). Handbook of research in mathematics teaching and learning. New York: Macmillan, 1992. p.147-164

FERNANDEZ, M.; ZILLIOX, J. Investigating approaches to lesson study in prospective 
mathematics teacher education. In: HART, L.; ALSTON, A.; MURATA, A. (ed.). Lesson study research and practice in mathematics education. Dordrecht: Springer, 2011. p.85-102

FERREIRA, R.A.T.F.; VALE, I.; PIMENTEL, T. Conhecimentos e práticas profissionais de professores de matemática. In: FERNANDES, J.A.; MARTINHO, M.H.; TINOCO, J.; VISEU, F. (ed.). Atas do XXIV Seminário de Investigação em Educação Matemática. Braga: APM \& CIEd da Universidade do Minho, 2013.

FIORENTINI, D.; NACARATO, A. M. (org.). Cultura, formação e desenvolvimento profissional de professores que ensinam matemática. São Paulo: Musa Editora, 2005.

FUJII, T. Designing and adapting tasks in lesson planning: a critical process of lesson study. ZDM Mathematics Education, n. 48, p. 411-423, 2016.

GATTI, B. A.; NUNES, M. M. R. (org.). Formação de professores para o ensino fundamental: estudo de currículos das licenciaturas em pedagogia, língua portuguesa, matemática e ciências biológicas. São Paulo: FCC/DPE, 2009.

HUANG, R.; LI, Y. Pursuing excellence in mathematics classroom instruction through exemplary lesson development in China: A case study. ZDM-The International Journal on Mathematics Education, n. 41, p. 297-309, 2009.

ISODA, M.; STEPHENS, M., OHARA, Y.; MIYAKAWA, T. (ed.) Japanese lesson study in mathematics: Its impact, diversity and potential for educational improvement. Singapore: World Scientific, 2007.

LEWIS, C. Lesson study: A handbook of teacher-led instructional change. Philadelphia, PA: Research for Better Schools, 2002.

LEWIS, C.; PERRY, R.; HURD, J. Improving mathematic instruction through lesson study: A theoretical model and North American case. Journal of Mathematics Teacher Education, n.12, p. 285-304, 2009.

MONTERO, L. A construção do conhecimento profissional docente. Trad. Armando P. Silva. Lisboa: Instituto Piaget, 2005.

MURATA, A. Introduction: Conceptual overview of lesson study. In: HART, L.; ALSTON, A.; MURATA, A. (ed.). Lesson study research and practice in mathematics education. Dordrecht: Springer, 2011. p. 01-12

NÓVOA, A. Formação de professores e profissão docente. In: NÓVOA, A. (ed.). Os professores e a sua formação. $2^{a}$ ed., Lisboa: Dom Quixote, p.15-33, 1995.

ROLDÃO, M.C. Currículo, didáticas e formação de professores: Triangulação esquecida. In: OLIVEIRA. M.R. Professor: formação, saberes e problemas. Porto: Porto Editora, 2014.

OLSON, J.; WHITE, P.; SPARROW, L. Influence of lesson study on teachers' mathematics pedagogy. In: HART, L.; ALSTON, A.; MURATA, A. (ed.). Lesson study research and practice in mathematics education. Dordrecht: Springer, p. 39-58, 2011.

PIRES, M.C.V. Materiais curriculares na construção do conhecimento profissional do professor de matemática. 2005. Tese (Dourado em Perspectivas Didácticas en Áreas 
Curriculares), Universidade de Santiago de Compostela - Departamento de Didáctica e Organización Escolar.

PONTE, J. Da formação ao desenvolvimento profissional. In: APM (ed.). Actas do ProfMat 98. Lisboa: APM, p.27-44, 1998.

PONTE, J.P. Didácticas específicas e construção do conhecimento profissional. In: Tavares, J.; Pereira, A.; Pedro, A.P.; Sá, H.A. (ed.). Investigar e formar em educação. Actas do IV Congresso da SPCE. Porto: SPCE. p. 59-72, 1999.

PONTE, J.P. Estudando o conhecimento e o desenvolvimento profissional do professor de matemática. In: Planas, N. (ed.). Teoria, crítica y prática de la educación matemática. Barcelona: GRAO, p. 83-98, 2012.

PONTE, J.P. Formação dos professores de Matemática: Perspectivas atuais. In: PONTE, J.P. (ed.). Práticas profissionais dos professores de matemática. Lisboa: Instituto de Educação da Universidade de Lisboa, p.343-360, 2014.

PONTE, J.P.; BAPTISTA, M.; VELEZ, I.; COSTA, E. Aprendizagens profissionais dos professores através dos estudos de aula. Perspectivas da Educação Matemática, n.5, p.724, 2012.

PONTE, J.P.; OLIVEIRA, H. Remar contra a maré: A construção do conhecimento e da identidade profissional na formação inicial. Revista de Educação, n.11, v.2, p.145-163, 2002.

PONTE, J.P.; QUARESMA, M.; MATA-PEREIRA, J.; BAPTISTA, M. O estudo de aula como processo de desenvolvimento profissional de professores de matemática. BolemaBoletim de Educação Matemática, n.30, v.56, p. 868-891, 2016.

PONTE, J.P.; QUARESMA, M.; MATA-PEREIRA, J.; BAPTISTA, M. Estudos de aula para promover o desenvolvimento profissional do professor. In: LOSS, A.; CAETANO, A.P.; PONTE, J.P. (ed.). Formação de professores no Brasil e em Portugal: Pesquisas, debates e práticas. Curitiba: Appris, p. 227-250, 2015.

PONTE, J.P.; QUARESMA, M.; MATA-PEREIRA, J.; BAPTISTA, M. Exercícios, problemas e explorações: Perspetivas de professoras num estudo de aula. Revista Quadrante. v.24, n. 2, 2015.

PONTE, J.P.; QUARESMA, M.; BAPTISTA, M.; MATA-PEREIRA, J. Os estudos de aula como processo colaborativo e reflexivo de desenvolvimento profissional. In: SOUSA, J.; CEVALLOS, I. (ed.). A formação, os saberes e os desafios do professor que ensina Matemática (Curitiba: Editora CRV, p. 61-82, 2014.

QUARESMA, M.; PONTE, J.P. Comunicação e processos de raciocínio: aprendizagens profissionais proporcionadas em estudos de aula. In: Congresso sobre Investigações em Educação Matemática. Anais... Evora, 2015.

RIBEIRO, A. J.; CURY, H. N. Álgebra para a formação do professor: explorando conceitos de equação e de função. Belo Horizonte: Autêntica, 2015.

RIBEIRO, A. J.; OLIVEIRA, F. A. P. V. S. Conhecimentos mobilizados por professores ao planejarem aulas sobre equações. Zetetiké, Campinas, v. 23, n. 44, p. 311-327, 2015. 
RICHIT, A. Apropriação do Conhecimento Pedagógico-tecnológico em Matemática e a Formação Continuada de Professores. 279 f. Tese (Doutorado em Educação Matemática). Universidade Estadual Paulista, Rio Claro, 2010.

ROLDÃO, M.C. Função docente: natureza e construção do conhecimento profissional. Revista Brasileira de Educação, n.34, v.12, p.94-103, jan.abri.2007. Disponível em: <http://www.scielo.br/pdf/rbedu/v12n34/a08v1234>.

SIBBALD, T. The relationship between lesson study and self-efficacy. School Science and Mathematics, n.109, v.8, p. 450-460, 2009.

SCHOENFELD, A.H. What makes for powerful classrooms, and how can we support teachers in creating them? A story of research and practice productively intertwined. Educational Researcher, n.43, v.8, p. 404-412, 2014.

SHULMAN, L. Knowledge and teaching: foundations of the new reform. Harvard Educational Review, n. 57, p. 4-14, 1987

SHULMAN, L. Those Who Understand: Knowledge Growth in Teaching. Educational Researcher. v.15, n. 2., p.4-14, Feb.1986.

STIGLER, J.W.; HIEBERT, J. Lesson study, improvement and the importing cultural routines. ZDM Mathematics Education, n.48, v.4, p. 581-587, 2016.

\section{NOTAS}

1 Em Portugal, o ensino básico inclui o $1 .^{\circ}$ ciclo (1. ${ }^{\circ}$ ao $4 .^{\circ}$ ano), $2 .^{\circ}$ ciclo $\left(5 .^{\circ}\right.$ e $6 .^{\circ}$ ano) e $3 .^{\circ}$ ciclo $\left(7 .^{\circ}\right.$ ao $9 .^{\circ}$ ano).

2 O detalhamento destes estudos de aula e os seus resultados são discutidos nos trabalhos de Ponte et al. (2014), Ponte et al. (2015) e Ponte et al. (2016), entre outros trabalhos produzidos.

3 Todos os nomes expressos no texto são fictícios.

4 Manuais escolares são materiais equivalentes ao livro didático no Brasil.

Submetido: $23 / 01 / 2018$

Aprovado: 05/12/2019

Contato:

Avenida Sete de Setembro, n. 222, Apto. 92 - Centro

Erechim $\mid$ RS $\mid$ Brasil

CEP 99.700-300 